\title{
AGENTE COMUNITÁRIO DE SAÚDE: QUESTÕES AMBIENTAIS E PROMOÇÃO DA SAÚDE EM COMUNIDADES RIBEIRINHAS
}

\author{
COMMUNITY HEALTH AGENT: ENVIRONMENTAL ISSUES AND PROMOTING HEALTH IN RIVERSIDE \\ COMMUNITIES
}

\author{
Natiane Carvalho Silva ${ }^{1}$ \\ Cristina Setenta Andrade ${ }^{2}$
}

Resumo No presente artigo, discutem-se as concepções de saúde e ambiente de agentes comunitários de saúde (ACSs) atuantes em duas comunidades ribeirinhas do eixo Ilhéus-Itabuna, sul da Bahia, Brasil, e suas atividades de promoção da saúde voltadas para o ambiente. Foram analisadas entrevistas semiestruturadas de 14 ACSs, tratadas com a técnica do discurso do sujeito coletivo proposta por Lefèvre e Lefèvre (2005). Nos discursos, os ACSs revelaram uma concepção ampla de saúde (qualidade de vida e direito) e relacionaram o ambiente ao território, embora o concebam como lugar onde as pessoas vivem. Também fazem relação entre saúde e melhorias no ambiente, e apesar de viverem e trabalharem em um território com problemas ambientais graves, suas atividades voltadas para o ambiente são pontuais e de conduta individual. Nessa perspectiva, reorientando o processo de trabalho, os ACSs indicam a capacidade de criar novas formas de relação entre ambiente e saúde. Potencializar esses atores que vivem na cena da tensão dos vários territórios em que transitam, valorizando seus saberes e sua vivência do(no) ambiente onde moram ou trabalham, pode ser o primeiro passo na direção da mudança, com a reorientação das práticas sanitárias e do modelo assistencial.

Palavras-chave território; promoção da saúde; Estratégia Saúde da Família; agente comunitário de saúde; problemas ambientais.
Abstract This article discusses the health and environmental concepts of community health agents (CHAs) working in two riverside communities in the Ilhéus-Itabuna axis, in southern Bahia, Brazil, and their health promotion activities focused on the environment. Semi-structured interviews carried out among 14 CHAs were analyzed using the collective subject discourse technique proposed by Lefèvre and Lefèvre (2005). In their discourses, the CHAs proved to have a broad view of health (quality of life and rights) and related the environment to the territory, although they consider this as the place where people live. They also relate health to environmental improvements, and although they live and work in a territory where there are serious environmental issues, they undertake environment-related activities only occasionally and individually. From this perspective, reorienting the work process, the CHAs show they are able to create new forms of relationship between the environment and health. Leveraging these players, who live on the scene of the tension of the several territories they transit in, valuing their knowledge and their experience of (in) the environment where they live or work, can be the first step taken toward change, with the reorientation of the health practices and of the health care model.

Keywords territory; health promotion; Family Health Strategy; Community Health Agent; environmental problems. 


\section{Introdução}

Os paradigmas sanitários foram influenciados pelo modelo econômico vigente no Brasil. São exemplos disso a proposta higienista para diminuição dos indicadores de doenças infecciosas e parasitárias que interferiam na agroexportação do país e a proposta privatista, com enfoque na doença, iniciando a assistência aos agravos dos trabalhadores e incentivando o crescimento da indústria farmacêutica e de equipamentos. Estes paradgimas fomentaram no imaginário da população a concepção de saúde como ausência de doença.

O sistema de saúde brasileiro - Sistema Único de Saúde (SUS) -, desenhado a partir dos amplos movimentos sociais pela democratização do acesso à saúde e instituído pela Constituição Federal de 1988 (Brasil, 1988), fundamenta-se no conceito ampliado de saúde. Privilegia a vigilância da saúde como modelo e práticas sanitárias que têm no enfoque por problemas, organização da comunidade, educação e saúde e na intersetorialidade alguns de seus instrumentos. Prioriza a atenção primária por meio da Estratégia Saúde da Família (ESF).

Na ESF, uma equipe fica responsável por uma área de abrangência, entendida como um território dinâmico de produção do cuidado. Dentre os membros da equipe de saúde da família, são os agentes comunitários de saúde (ACSs) que desenvolvem um trabalho na perspectiva da promoção da saúde, devendo intervir nos fatores ambientais que repercutem na saúde individual e coletiva.

Sabe-se que, nas periferias urbanas, muitos fatores que afetam a saúde da população têm relação direta com as condições de vida resultantes do modelo de desenvolvimento em curso. Esses grupos são duplamente atingidos pelas iniquidades, pois estão excluídos dos processos de produção e consumo, mas expostos aos problemas ambientais urbanos (Opas/OMS, 1999) que derivam desses processos.

A concepção de ambiente - e sua relação com a saúde -, descrita no relatório final do I Seminário Nacional de Saúde e Ambiente com Controle Social (Brasil, 2003), considera-o como sistema socioecológico complexo, organizado hierarquicamente, diversificado (componentes sociais, culturais, históricos, biológicos, físicos e químicos) e que, além do fluxo energético, engloba os fluxos das relações sociais, como a afetividade.

Nessa perspectiva, considera-se que os agentes comunitários de saúde na ESF atuam na reorientação das práticas sanitárias, pois buscam identificar problemas e necessidades e intervir nos seus fatores determinantes e condicionantes. Como moradores das comunidades onde atuam, vivenciam as questões ambientais, sendo afetados por elas, não apenas no seu trabalho, mas no seu cotidiano. Portanto, as ações de promoção da saúde devem ser 
priorizadas pela equipe de saúde da família e principalmente pelos ACSs atuantes nesse território.

Este artigo 3 apresenta parte dos resultados da pesquisa que originou a dissertação de mestrado de uma das autoras, intitulada Paradigmas sanitários e problemas ambientais: os discursos dos agentes comunitários de saúde (Silva, 2008). O estudo, realizado em duas comunidades ribeirinhas, caracterizou as duas áreas quanto aos seus aspectos socioambientais e buscou encontrar respostas para as seguintes questões, que nortearam a pesquisa: qual a concepção que os ACSs têm de ambiente e de sua relação com a saúde? Os ACSs percebem a problemática ambiental como causadora de problemas de saúde? Quais atividades voltadas para o enfrentamento dos problemas ambientais eles desenvolvem? E quais são as dificuldades e facilidades que percebem no desenvolvimento de atividades voltadas para o ambiente? Por meio dessas perguntas buscou-se elucidar que paradigma sanitário tem norteado o fazer dos ACSs, refletindo-se sobre o potencial desses atores nas iniciativas de promoção da saúde com foco no ambiente.

Neste artigo, discutem-se as concepções de saúde e ambiente que os ACSs manifestam e suas atividades voltadas para o ambiente. O estudo pode contribuir para fornecer elementos e subsídios a programas de formação e educação permanente dos ACSs que contemplem a dimensão ambiental, buscando a construção de novas relações desses atores com o ambiente com vistas à promoção da saúde, reorientando seu processo de trabalho e apostando em novos modos de operar o cuidado em saúde a partir do ambiente.

\section{Metodologia}

O estudo investigou o trabalho de agentes comunitários de saúde relacionado aos problemas ambientais de duas comunidades ribeirinhas do eixo Ilhéus-Itabuna, no litoral sul da Bahia. Optou-se pela abordagem qualitativa, em um estudo de caráter exploratório e descritivo. A escolha das áreas levou em consideração similaridades em alguns aspectos socioambientais, como a distância de centros urbanos densamente construídos, a localização nas margens do rio Cachoeira (importante bacia hidrográfica da região) e o adensamento populacional a partir da crise na monocultura cacaueira regional, além da implantação de equipes de saúde da família.

Foram realizadas entrevistas com os agentes comunitários, gravadas em áudio digital, utilizando-se um roteiro semiestruturado previamente testado. Optou-se pelos ACSs por causa da peculiaridade de serem ao mesmo tempo membros da equipe de saúde e moradores dos territórios onde atuam, estando, portanto, na tensão entre as necessidades de saúde verificadas, 
os problemas ambientais vivenciados e a capacidade de resolução do sistema de saúde local.

Nas duas unidades existem ao todo, em atividade, 16 agentes. Desses, 15 concordaram em participar da pesquisa. Um dos ACSs foi entrevistado para a testagem do roteiro, e sua entrevista não foi utilizada na análise, restando 14 sujeitos. As entrevistas foram transcritas, sistematizadas previamente e analisadas pela técnica do discurso do sujeito coletivo (DSC) proposta por Lefèvre e Lefèvre (2005). Para a construção dos discursos-síntese, foram utilizados os operadores metodológicos: expressões-chave (ECH); ideia central ou categoria (IC); e redação dos discursos-síntese. A proposta do DSC busca, por meio dos discursos-síntese produzidos,

expressar a fala do social, rompendo, por um lado, com a tradição da pesquisa quantitativa que deforma a natureza eminentemente discursiva do pensamento para quantificá-lo e, por outro, com a tradição de pesquisa qualitativa que considera a fala do social como uma metalinguagem científico-acadêmica, que produz o discurso social pelo viés dos comentários descritivos, interpretativos e generalizadores do pesquisador (Lefèvre e Lefèvre, 2005, p. 28).

A pesquisa foi aprovada pelo Comitê de Ética em Pesquisa Envolvendo Seres Humanos da Universidade Estadual de Santa Cruz (Uesc).

\section{Paradigmas sanitários e a atuação de ACSs}

A ESF é a principal aposta do sistema de saúde brasileiro para a reorientação do modelo assistencial, que persiste com forte influência do 'flexnerianismo' para a construção de novos desenhos organizativos pautados na concepção positiva de saúde. Nesse contexto, os ACSs têm papel fundamental: constituem o 'elo' entre as necessidades sentidas no território e a organização de respostas do sistema de saúde local para essas necessidades. Por isso, cabe indagar a concepção de saúde dos ACSs e como ela afeta ou direciona as suas práticas sanitárias, aproximando-se do paradigma sanitário que norteia o seu fazer.

Em seus discursos, os ACSs revelam uma concepção ampla de saúde quando consideram saúde como qualidade de vida:

Saúde são as pessoas que têm condições de vida melhor. É um conjunto que envolve moradia, salário, saneamento básico em todos os sentidos, tanto econômico quanto social. É o bem-estar da pessoa, físico e mental; enfim, é o melhoramento do bem-estar de uma comunidade. Saúde é o fator fundamental da vida da pessoa, é a riqueza, é a motivação da vida da pessoa. Se a pessoa tem saúde, a pessoa tem 
tudo. Então, resumindo tudo, saúde para mim é qualidade de vida (DSC - Saúde como qualidade de vida, ACS 1, 2, 3, 4, 5, 6).

Os ACSs ampliam a concepção de saúde para a questão da saúde como um direito, coerente com o conceito de saúde da Reforma Sanitária institucionalizado no SUS e trabalhado nos manuais e normas da ESF. A relação saúde e melhorias no ambiente, presente nos discursos, também aparece (ainda que timidamente) nas normas e diretrizes do Programa de Agentes Comunitários de Saúde (Pacs) (Brasil, 1993) e da ESF (Brasil, 1997). No entanto, quando se referem aos problemas de saúde da comunidade, os ACSs concentram-se nas doenças e em seus agravos. A falta de saneamento básico, a baixa escolaridade, as inundações não foram referidas no elenco dos problemas de saúde identificados.

Percebe-se que os ACSs refletem essa tensão paradigmática presente no sistema de saúde brasileiro, considerado em transição, o qual, embora reconheça o papel dos determinantes e condicionantes sociais e econômicos na situação de saúde das pessoas, incluindo-se neles as questões ambientais no campo das ações e intervenções, concentra-se na doença (seja na prevenção, seja no diagnóstico ou na cura). Tal situação mostra que o avanço das últimas décadas no conceito de saúde pouco superou 'as forças' que sustentam o paradigma biomédico e o enfoque biológico dos conceitos de saúde e doença.

Noack (apud Ferraz, 1998) considera que assistimos a uma verdadeira crise paradigmática da saúde. Presenciamos o início de um movimento que caminha de um estágio da ciência biomédica normal para um estágio de uma perspectiva global - denominada pelo autor de paradigma socioecológico (em âmbito mundial) - que pode substituir o paradigma biológico, porém de maneira a integrá-lo.

Mendes (1993, 1999) considera que, no Brasil, a transição paradigmática prevê um período em que o velho (paradigma biomédico) convive com o novo (paradigma da produção social da saúde) de maneira a substituí-lo na explicação dos problemas e na fundamentação das respostas sociais organizadas (práticas sanitárias).

$\mathrm{O}$ avanço na reorientação do modelo de saúde baseia-se, entre outros fatores, em mudanças no processo de trabalho dos profissionais de saúde, com ampliação do olhar para além do indivíduo, da medicalização e das rotinas estabelecidas, e para intervenções mais voltadas às mudanças no território e nos problemas ambientais que repercutem na situação de saúde da comunidade, na perspectiva da promoção da saúde.

Ianni e Quitério (2006) afirmam que, com a importância crescente das doenças relacionadas aos estilos de vida e ao meio ambiente, e tendo em perspectiva a complexidade dessas relações, faz-se necessário que o setor 
saúde desenvolva um novo olhar sobre a população cuja sistematização permitirá propor intervenções para além das práticas curativas e preventivas, aproximando-se da promoção da saúde. Esse é o grande desafio da ESF, que tem os ACSs com atuação essencialmente no território, de potencializar a promoção da saúde considerada estratégica para a reversão do modelo assistencial brasileiro vigente.

A atenção básica é o nível de excelência para a inclusão da problemática ambiental no âmbito do SUS mediante a ESF. No entanto, essa possibilidade deve ser potencializada principalmente pelos ACSs que fundamentam suas práticas de saúde na lógica da promoção da saúde (prevenção, incorporação dos riscos e degradação ambiental e atuação na esfera territorial). Por meio da ESF, a temática ambiental pode ser inserida transversalmente nas políticas do SUS, com forte componente da promoção da saúde (Brasil, 2003).

Conforme apontam Ferreira et al. (2009), quando o trabalho do ACS possibilita produzir um processo de reestruturação produtiva, o ACS se desterritorializa, enquanto sujeito, pois se permite transitar de um modelo centrado em procedimentos de prevenção de riscos e agravos para desenvolver um processo de trabalho apoiado nas necessidades da comunidade. Tal perspectiva potencializa as tecnologias relacionais do seu trabalho vivo para inventar e criar formas de cuidado singulares que incluem ambientes saudáveis no território.

\section{Concepções de ACS sobre ambiente}

A concepção de ambiente predominante nos discursos dos agentes comunitários de saúde o considera como um lugar onde as pessoas vivem. O sentido dado pelos ACSs se aproxima mais do conceito de espaço de Milton Santos (1979; 1997), para quem o espaço

é uma instância da sociedade (...) a essência do espaço é social (...) o espaço não pode ser apenas formado pelas coisas, objetos geográficos, naturais e artificiais (...) o espaço é tudo isso e mais a sociedade: cada fração da natureza abriga uma fração da sociedade atual (Santos, 1997, p. 1).

Percebe-se uma concepção ampla de ambiente nos discursos dos ACSs ao relacionarem ambiente e território:

Ambiente é o local onde nós vivemos. Porque o meio ambiente que a gente vive é o mesmo assim do outro, das matas. Ambiente é o local mesmo onde a gente vive, eu entendo que é onde vivemos, o lugar que trabalhamos. É também tipo uma família, uma união. Todo lugar onde nós vivemos é o ambiente, onde nós frequen- 
tamos é o ambiente, onde nós estamos é um ambiente. Então eu acho que ambiente é isso, é o lugar onde envolve todo o sistema ali, o lugar que a pessoa mora, o que ela faz, o que ela usa pra sobreviver. Então, resumindo, qualquer lugar onde exista uma pessoa é um ambiente, não sei se tem a ver com habitat. Eu também penso em preservação, essas coisas (DSC - O ambiente é um lugar, ACS 7, 8, 9, 10, $12,13,14)$.

Retomando os modelos na relação saúde e ambiente propostos no I Seminário Nacional de Saúde e Ambiente com Controle Social (Brasil, 2003), percebe-se que os ACSs concebem o ambiente como um sistema socioecológico, de alta complexidade, cujos componentes são muito diversificados (sociais, culturais, históricos, biológicos, físicos, químicos) com fluxos energéticos e relações sociais.

Nessa perspectiva, os agentes comunitários de saúde conseguem ampliar a noção difusa de ambiente presente nas normas e diretrizes da ESF e mostram a capacidade de se criarem novas formas de relação entre o ambiente e a saúde. Trata-se de ajustar o caráter coletivo do binômio saúde-doença e o sentido do 'lugar' nesse coletivo, como espaço organizado e privilegiado para análise e intervenção, identificando as condições de saúde e seus determinantes culturais, sociais e ambientais, dentro de ecossistemas modificados pelo trabalho e pela intervenção humana (Minayo, 2002).

\section{O território do ACS e as atividades voltadas para o ambiente}

A noção de território difundida na saúde coletiva advém do conceito de espaço 'herdado' da geografia humana. O território, para a ESF, define-se como o espaço de atuação de uma equipe de SF, identificada como área de abrangência para o Sistema de Informação da Atenção Básica (Siab). Conforme Monken e Barcellos (2005, p. 898), “A territorialização consiste em um dos pressupostos da organização dos processos de trabalho e das práticas de saúde, considerando-se uma atuação em uma delimitação espacial previamente determinada". No entanto, a exemplo de outras iniciativas no SUS, muitas vezes reduz o conceito de espaço, utilizado de forma administrativa, negligenciando-se o potencial desse conceito para a identificação de problemas de saúde e de propostas de intervenção (Monken e Barcellos, 2005).

O entendimento da saúde como resultado da produção social, que fundamenta a ESF, priorizando a promoção da saúde, amplia a importância de "esclarecer as mediações que operam entre as condições reais em que ocorre a reprodução dos grupos sociais no espaço e a produção da saúde e da doença" (Monken e Barcellos, 2005, p. 899). Destaca-se ainda que o reconhecimento do território é fundamental para a organização das práticas de vigilância da 
saúde, identificando e interpretando a organização e a dinâmica das populações que nele habitam, as condições de vida da população e as diferentes situações ambientais que as afetam (Monken e Barcellos, 2007).

Ao caracterizar o território onde vivem e/ou trabalham, os agentes comunitários de saúde descreveram graves problemas socioambientais que repercutem na saúde das famílias que acompanham. Apesar das singularidades, as duas áreas do estudo exibem problemas socioambientais comuns que aparecem nos discursos dos ACSs das duas comunidades.

A falta de saneamento básico, de pavimentação adequada, a degradação do rio e a violência são problemas comuns, destacados pelos agentes comunitários de saúde. Ao considerarem a violência como um problema ambiental, os ACSs sinalizam uma ampliação do olhar nas relações saúde-ambiente para além do saneamento clássico (Minayo et al., 1999), herdado do sanitarismo da saúde pública.

Os problemas descritos pelos agentes comunitários de saúde foram listados e classificados segundo o documento Atenção Primária Ambiental (APA) da Organização Pan-Americana da Saúde (Opas), que propõe uma tipologia dos problemas ambientais em áreas urbanas (Opas/OMS, 1999).

\section{Quadro 1}

Tipologia dos problemas ambientais urbanos nos discursos dos ACSs de duas comunidades ribeirinhas do eixo Ilhéus-Itabuna, Bahia, Brasil (Opas/OMS, 1999)

\begin{tabular}{lcc}
\hline Problemas ambientais urbanos & Nova Ferradas & Salobrinho \\
\hline Contaminação atmosférica (industrial e doméstica) & $\mathrm{X}$ & \\
Contaminação acústica & $\mathrm{X}$ & \\
Contaminação da água & $\mathrm{X}$ & $\mathrm{X}$ \\
Abastecimento de água potável & $\mathrm{X}$ & $\mathrm{X}$ \\
Resíduos sólidos & $\mathrm{X}$ & $\mathrm{X}$ \\
Uso indevido do solo & $\mathrm{X}$ & $\mathrm{X}$ \\
Vetores de doenças & $\mathrm{X}$ & $\mathrm{X}$ \\
Ruas sem pavimentação & & $\mathrm{X}$ \\
Segurança e qualidade dos alimentos & $\mathrm{X}$ & $\mathrm{X}$ \\
Incinerações não autorizadas & & $\mathrm{X}$ \\
Falta de áreas verdes & $\mathrm{X}$ & \\
Manejo inadequado dos canais de drenagem & & \\
Desastres naturais (enchentes) & & \\
\hline
\end{tabular}

Fonte: Os autores.

O Quadro 1 demonstra que nas áreas do estudo estão presentes a maioria dos problemas ambientais urbanos classificados pela Opas/OMS em 1999, e são percebidos nos discursos dos ACSs. Tal situação identificada é de índole 
local e tem repercussão direta na saúde e na qualidade de vida da comunidade de onde se originam.

Os problemas descritos evidenciam o contraste presente na maioria das cidades brasileiras onde, no centro, concentram-se áreas providas de melhorias e equipamentos urbanos, e em regiões afastadas dos centros estão os bairros periféricos, em áreas negligenciadas pelo poder público, portanto, desprovidas de ordenamento territorial e infraestrutura adequadas para instalação de moradias. Ou ainda, como acontece em uma das áreas do estudo, na expansão urbana para a área agrícola.

Segundo o relatório final da I Conferência Nacional de Saúde e Ambiente com Controle Social (Brasil, 2003), não pode ser considerado desordenado o processo de ocupação dos solos nas periferias urbanas, pois ele segue a 'ordem' dada pela inserção dos agrupamentos humanos segundo as classes sociais. A baixa qualidade de vida dos habitantes das cidades brasileiras e os indicadores negativos de saúde resultam do tipo de ocupação observada na maioria das cidades, responsável pela degradação do ambiente.

Com a emergência das questões ambientais contemporaneamente, os profissionais de saúde devem ampliar suas ações na perspectiva de incorporar à sua prática as ações de promoção da saúde, pois, conforme advertem Ianni e Quitério (2006), não apenas as interrelações entre degradação ambiental e saúde já estão estabelecidas: também são vitais a manutenção da integridade dos ecossistemas e da preservação da biodiversidade, garantindo a continuidade dos serviços ambientais e o suporte ao modo de vida de comunidades tradicionais.

O ACS é o membro da equipe de saúde da família (SF) com maior potencial para intervir nos problemas ambientais, uma vez que estes o afetam em seu trabalho e em sua vida. No entanto, essa potencialidade deve ser estimulada. Questionados sobre as atividades voltadas para o ambiente, os ACSs descreveram algumas atividades pontuais e de conduta individual. Não houve relato de atividades sistematizadas ou instituídas por eles ou pela equipe de SF sobre os problemas ambientais. As atividades voltadas para a promoção da saúde e as intervenções no ambiente foram consideradas, nos discursos dos agentes, secundárias, difíceis ou até mesmo desconhecidas.

É instigante constatar que mesmo vivendo e trabalhando em um território com problemas ambientais graves e que incidem sobre a saúde das pessoas, os ACSs são pouco afetados pelas questões ambientais que venham a produzir saúde e não desenvolvem o cuidado voltado para o ambiente em sua prática cotidiana. Esse fato pode revelar um distanciamento dos ACSs do ambiente onde moram e trabalham. Por meio da captura da hegemonia do saber biomédico, o conhecimento que o ACS traz do lugar onde vive e das necessidades sentidas pela comunidade fica em segundo plano diante 
da medicalização e ações programáticas impostas nas práticas sanitárias na equipe de saúde da família.

Tal perspectiva coaduna-se com Ferreira et al. (2009), quando sinalizam a fragilidade do ACS para deflagrar os processos de reestruturação produtiva no seu modo de operar o trabalho em saúde. Pouco se avançou com a ampliação do sentido dado à territorialização praticada na ESF para além da delimitação da área de abrangência, que reconhece a população, o ambiente e a dinâmica social em territórios específicos com necessidades e problemas definidos.

Reconhecidas pelas equipes, nesses territórios as intervenções sobre os problemas seriam também sobre as condições de vida da população, como convergência das ações de promoção, prevenção e atenção (Santos e Rigotto, 2011).

\section{A promoção da saúde e o enfrentamento dos problemas ambientais: educação em saúde (ES) e organização comunitária (OC)}

Os agentes comunitários de saúde atuam em territórios com graves problemas socioambientais que repercutem na saúde das famílias que acompanham. No entanto, mesmo atuando diariamente num território com graves problemas ambientais e sanitários interrelacionados, descritos pelos próprios agentes comunitários de saúde, no escopo de sua prática prevalecem as atividades centradas para o acompanhamento e a prevenção de riscos e agravos, com poucas ações voltadas para a promoção da saúde. A prevenção e a promoção, por vezes, aparecem nos discursos dos ACSs como sinônimos, mostrando que a promoção da saúde como prática sanitária ainda é um desafio.

Como ressalta Ferraz (1998), o conceito de promoção da saúde tem evoluído com o próprio conceito de saúde, no sentido de incorporar a dimensão ambiental na explicação e no enfrentamento dos problemas de saúde. No campo das práticas sanitárias, isso significa continuar as ações preventivas e de controle de saúde que estão afetas aos cuidados médicos e grupos de risco (próprios do paradigma biotecnológico), abrindo espaços, ao mesmo tempo, para novas intervenções de efetiva promoção da saúde, intervenções estas intersetoriais.

A respeito das atividades de promoção da saúde que eles realizam em suas microáreas e como enfrentam os problemas ambientais presentes, os discursos variaram entre o desconhecimento do que é promoção da saúde, o desenvolvimento de ações pontuais de educação e saúde até a sensação de impotência diante da complexidade dos problemas experienciados.

Uma possível explicação pode ser encontrada nos processos de formação de ACS. Nos cursos introdutórios, sobre a relação saúde e ambiente, predomina o paradigma identificado por Tambellini e Câmara (1998) como 
antropocêntrico - como exemplo, o modelo da História Natural da Doença, de Leavell e Clark (1965), apud Tambellini e Câmara (1998), em que as categorias agente, hospedeiro e ambiente estão em um mesmo plano, destituídas de hierarquia. Nesse modelo, a promoção da saúde aparece como um momento anterior ao da prevenção e está ligada a grupos específicos expostos a determinados fatores de risco (ambientais, genéticos).

Nos discursos sobre as ações desenvolvidas em promoção da saúde, os ACSs não conseguiram identificar o seu papel estratégico no conhecimento do território. A mobilização da comunidade na perspectiva de provocar "melhorias no meio ambiente" (Brasil, 1997, p. 18) também é revelado nos discursos como 'algo a ser feito por alguém' que perpassa a fragilidade do agente comunitário de saúde diante das necessidades ambientais.

O agente comunitário de saúde também refere a falta de apoio institucional como um dos motivos para a não realização de atividades de promoção da saúde, ou ainda a falta de estímulo e participação dos demais membros da equipe de SF.

Tal situação revela que o trabalho do ACS ocorre muito ancorado na equipe de SF, o que acaba minimizando a importância das intervenções no território. Suas ações ficam restritas ao acompanhamento de doentes, numa espécie de supervisão domiciliar da prescrição médica para os usuários dos programas de grupos específicos (hipertensos, diabéticos, crianças menores de dois anos, gestantes, tuberculosos, por exemplo).

Os ACSs confundem promoção da saúde com prevenção de doenças. E referem-se a atividades preventivas como se fossem atividades de promoção, apesar da clareza na concepção de saúde que expressaram nos discursos:

A gente observa o cartão, as vacinas atrasadas, a gente pede a essas mães para que elas levem o filho à unidade pra dar as vacinas faltantes, algumas vitaminas para que evite os problemas, evite as doenças. O próprio idoso tem a vacina da gripe, que tem que tomar, é uma prevenção. Com os adolescentes também a gente fala muito sobre as doenças sexualmente transmissíveis. Se for criança, tem que tomar as vacinas. Também na visita domiciliar fazemos o acompanhamento de toda família cadastrada, hipertensos, diabéticos, gestantes, crianças de zero a dois anos (DSC - Atividades dos ACS voltadas para prevenção de doenças, ACS 9, 11).

Stachtchencko e Jenicek (1990), apud Ferraz (1998), consideram que as noções de promoção da saúde e prevenção de doenças estão baseadas em paradigmas diferentes. A prevenção se baseia na concepção de risco ou probabilidade de se tornar doente, e os estudos clínicos e as intervenções visam em geral a grupos restritos. Já a noção de promoção da saúde se preocupa mais frequentemente com os múltiplos aspectos ligados a estilos e condições de vida. 
Carvalho (2005) defende a ideia de que o setor da saúde tem um aporte fundamental para a implementação de intervenções voltadas para o que chama de 'promoção da saúde lato sensu' (ações garantidas mediante políticas sociais, públicas e estruturais), mas não deve adjudicar para si a responsabilidade por todas as políticas públicas e ações que tenham por finalidade, em última instância, a saúde dos indivíduos e coletivos.

Para Carvalho (2005), é importante que o setor saúde privilegie as ações de 'promoção da saúde stricto sensu' (estratégias dentro do setor saúde que visem à implantação de políticas públicas saudáveis, ações intersetoriais, produção de ambientes saudáveis). Nessa perspectiva, para reversão dos problemas ambientais encontrados, as ações situam-se no âmbito da promoção da saúde stricto sensu, em que o setor saúde deve deflagrar o processo de intervenção intersetorial, visando à produção de ambientes saudáveis.

Dentre as atividades de promoção da saúde relatadas pelos ACSs, cabem destaque as atividades educativas pontuais desenvolvidas durante a visita, permeadas por uma concepção de educação em saúde pautada na transmissão de informações aprendidas com os técnicos de saúde, por meio da qual os agentes comunitários de saúde reproduziam tarefas planejadas por outros, caracterizando uma atividade prescritiva e normativa (Trapé e Soares, 2007).

A concepção prescritiva da educação em saúde tem por finalidade mudar comportamentos considerados inadequados para se conservar a saúde ou evitar a doença e se pauta na culpabilização do indivíduo por ficar doente. Segundo Trapé e Soares (2007), busca-se assim melhorar a situação de vida das pessoas mediante recursos individuais sem que se contestem a estrutura e a dinâmica do modo de produção, que engendram as raízes dos problemas ambientais e de saúde, e uma concepção de educação como uma construção coletiva do processo educativo em saúde que busca se ampliar para a esfera dos direitos e da construção da cidadania.

Nessa perspectiva, os preceitos da educação ambiental brasileira são caracterizados pelo engajamento e luta na constituição da cidadania, criticada por Reigota (2007), para quem “o movimento histórico da educação ambiental brasileira tem apontado para a desconstrução do 'ambiental' na sua definição e não para ampliá-la. A educação ambiental procura ser educação sem quaisquer outros adjetivos" (Reigota, 2007, p. 159).

A educação, seja em saúde, seja ambiental, deve partir de um processo de reflexão por meio da (re)construção da história do território, identificando as injustiças (iniquidades) socioambientais do contexto local (modelo econômico baseado na monocultura de exportação) e sua interface com a Saúde Coletiva, revelada pelo perfil socioambiental e epidemiológico das comunidades. A educação ambiental e a educação em saúde são possibilidades de construção da autonomia dos sujeitos para a luta e constituição da 
cidadania, com base nos problemas e nas necessidades com aprendizagem significativa que afetem os sujeitos na promoção de movimentos de mudança.

O ACS, diante das necessidades ambientais e de saúde em suas comunidades, poderá utilizar-se de dispositivos instituintes criativos e construtores para potencializar a ESF como estratégia capaz de articular, no nível local, a mobilização da comunidade em busca de condições dignas de vida.

A organização comunitária na promoção da saúde revelou a existência de movimentos organizados como associação de moradores, conselhos locais ou outros, porém com poucos ou mesmo com a ausência de ações em busca de melhorias.

As relações entre saúde e ambiente envolvem também a organização comunitária, discutindo-se nas conferências internacionais de promoção da saúde, principalmente em Ottawa (Brasil, 2002), o empowerment em defesa dos seus direitos.

Carvalho (2005) considera que o conceito de empowerment comunitário contribui para consolidar em nosso país práticas sanitárias que procuram não só concretizar a saúde como um direito, mas também privilegiar a capacidade dos sujeitos de viverem com autonomia. Afirma ainda que “a utilização dessa categoria nos é útil em diversas áreas: na educação à saúde, na gestão das instituições e em estratégias voltadas para a participação comunitária" (Carvalho, 2005, p. 157).

$\mathrm{O}$ autor também defende a denominação de 'empowerment social' com o intuito de sinalizar que a esfera comunitária é apenas uma de suas múltiplas dimensões (pessoais, intersubjetivas, coletivas e macropolíticas); além disso, pode contribuir para superar duas das grandes debilidades do movimento da promoção da saúde, que são, segundo Carvalho (2005), a fragilidade das propostas de reorganização dos serviços assistenciais e a falta de alternativa para a prática clínica.

\section{Conclusão}

O ACS, considerado o 'elo' e, portanto, 'porta-voz' das necessidades de saúde da comunidade, tem reproduzido em sua prática o privilégio das atividades de acompanhamento de doentes e prevenção de doenças (nos moldes do flexnerianismo). Mesmo vivendo em um território com problemas socioambientais que o afetam no seu trabalho e, principalmente, no seu "modo de andar a vida" (Mendes, 1999, p.15), percebe-se que essa realidade não é capaz de deflagrar, no ACS, novas formas de se relacionar com o ambiente onde vive.

Apesar da existência de problemas ambientais urbanos que incidem sobre a saúde das comunidades, os ACSs não utilizam dispositivos capazes 
de minimizar tal situação. As atividades voltadas para a promoção da saúde de caráter mais amplo e o enfrentamento dos problemas ambientais não conseguem se sobrepor às ações programáticas. Em parte, a própria ESF, ao ser concebida, não deu ênfase às questões ambientais, apesar de ter sido implantada na década de 1990, período de intenso debate mundial sobre o tema.

A formação dos agentes comunitários de saúde contribui para reproduzir as práticas sanitárias 'medicalizantes' e perpetuar o paradigma biomédico, visto que nos treinamentos predominaram o enfoque das doenças, agravos e o acompanhamento de grupos específicos (conforme os preceitos do sanitarismo), com abordagem tímida sobre a relação saúde e ambiente, ou mesmo sobre saúde ambiental na perspectiva da educação para a cidadania, contemplando a dimensão ambiental, já que o território é o espaço privilegiado das ações de promoção da saúde.

Outra consideração importante refere-se ao processo de territorialização desenvolvido pelas equipes na ESF. Conforme asseguram Santos e Rigotto (2011), é necessária a ampliação do sentido de territorializar, como capacidade de reconhecer o contexto sócio-histórico específico e atuar sobre ele; construir vínculos com o lugar; superar os limites da unidade de saúde e das práticas clínicas convencionais; e proceder à incorporação efetiva do paradigma da promoção da saúde e da participação.

Nesse sentido, as questões ambientais vivenciadas no território do ACS abrem espaço para novas formas de cuidado e intervenção em saúde, pois não encontram respostas institucionalizadas nas ações programáticas, tampouco explicações pela lógica biomédica. Potencializar esse ator que vive na cena da tensão entre os vários territórios em que transita, valorizando os saberes que utiliza no cuidado prestado às famílias, assim como sua vivência no ambiente onde mora e/ou trabalha, pode ser o primeiro passo na direção de mudança e reorientação das práticas sanitárias.

\section{Notas}

1 Professora assistente do Departamento de Ciências da Saúde da Universidade Estadual de Santa Cruz (Uesc), Ilhéus, Bahia, Brasil. Mestre em Desenvolvimento Regional e Meio Ambiente pela Universidade Estadual de Santa Cruz (Uesc).<ncsaragao@uesc.br> Correspondência: Universidade Estadual de Santa Cruz, Departamento de Ciências da Saúde, Pavilhão Jorge Amado, BR-415, Rodovia Ilhéus-Itabuna, km 16, $1^{\circ}$ andar, sala 3.105, CEP 45662-000, Ilhéus, Bahia, Brasil. 
2 Professora titular do Departamento de Ciências da Saúde da Universidade Estadual de Santa Cruz (Uesc), Ilhéus, Bahia, Brasil. Doutora em Saúde Pública pela Universidade de São Paulo (USP). <cristina70@uol.com.br>

3 Artigo elaborado com base na dissertação de mestrado Paradigmas sanitários e problemas ambientais: os discursos dos agentes comunitários de saúde, de autoria de Natiane Carvalho Silva, apresentada ao Programa de Pós-Graduação em Desenvolvimento Regional e Meio Ambiente, Rede Prodema, Universidade Estadual de Santa Cruz (Uesc), em março de 2008. Não houve financiamento externo. A pesquisa foi aprovada pelo Comitê de Ética em Pesquisa da Uesc.

\section{Referências}

BRASIL. Constituição da República Federativa do Brasil. Brasília, DF: Senado Federal, 1988.

. Ministério da Saúde. Normas e diretrizes dos agentes comunitários de saúde. Brasília, DF: Ministério da Saúde, 1993.

Ministério da Saúde. Promoção da saúde: Declaração de Alma-Ata, Carta de Ottawa, Declaração de Adelaide, Declaração de Sundsvall, Declaração de Santa Fé de Bogotá, Declaração de Jacarta, Rede dos Megapaíses, Declaração do México. Brasília, DF: Ministério da Saúde, 2002.

Ministério da Saúde. Conselho Nacional de Saúde. Relatório final. Eixo I - marco conceitual. In: . Seminário Nacional de Saúde e Ambiente com Controle Social, 1. Brasília, DF: Ministério da Saúde, 2003. p. 11-20.

- Ministério da Saúde. Secretaria de Assistência à Saúde. Coordenação de Saúde da Comunidade. Programa Saúde da Família: uma estratégia para a reorientação do modelo assistencial. Brasília, DF: Ministério da Saúde, 1997.

CARVALHO, Sérgio Resende. Saúde coletiva e promoção da saúde: sujeito e mudança. São Paulo: Hucitec, 2005.
FERRAZ, Sônia Terra. Promoção da saúde: viagem entre dois paradigmas. Revista de Administração Pública, Rio de Janeiro, v. 32, n. 2, p. 49-60, mar.-abr. 1998.

FERREIRA, Vitória S. et al. O processo de trabalho do agente comunitário de saúde e a reestruturação produtiva. Cadernos de Saúde Pública, Rio de Janeiro, v. 25, n. 4 , p. 898-906, abr. 2009.

IANNI, Aurea Maria Zöllner; QUITÉRIO, Luiz Antonio Dias. A questão urbana no Programa Saúde da Família: avaliação da estratégia ambiental numa política pública de saúde. Ambiente e Sociedade, São Paulo, v. 9, n. 1, 169-180, jan.-jun. 2006.

LEFÈVRE, Fernando; LEFÈVRE, Ana M. C. O discurso do sujeito coletivo: um novo enfoque em pesquisa qualitativa (desdobramentos). 2. ed. Caxias do Sul: Educs, 2005.

MENDES, Eugênio V. A construção da vigilância à saúde no distrito sanitário. In: ORGANIZAÇÃO PAN-AMERICANA DA SAÚDE (OPAS)/ORGANIZAÇÃO MUNDIAL DA SAÚDE (OMS). A vigilância à saúde no distrito sanitário. Brasília: Opas/OMS, 1993. p. 7-18. 
. A crise da saúde e as reformas do setor. In: Uma agenda para a saúde. 2. ed. São Paulo: Hucitec, 1999. p. 15-55.

MINAYO, Maria Cecília de Souza. Enfoque ecossistêmico de saúde e qualidade de vida. In: MINAYO, Maria Cecília de Souza; MIRANDA, Ary Carvalho de. (Orgs.). Saúde e ambiente sustentável: estreitando nós. Rio de Janeiro: Editora Fiocruz, 2002. p. 173187.

MINAYO, Maria Cecília de Souza et al. O programa institucional sobre saúde e ambiente no processo de desenvolvimento da Fundação Oswaldo Cruz. Anais da Academia Brasileira de Ciências, Rio de Janeiro v. 71, n. 2, p. 279-288, jun. 1999.

MONKEN, Maurício; BARCELLOS, Christovam. Vigilância em saúde e território utilizado: possibilidades teóricas e metodológicas. Cadernos de Saúde Pública, Rio de Janeiro, v. 21, n. 3, p. 898-906, maio-jun. 2005.

. O território na promoção e vigilância em saúde. In: FONSECA, Angélica Ferreira; CORBO, Ana Maria D'Andrea (Orgs.). o território e o processo saúde-doença. Rio de Janeiro: Escola Politécnica de Saúde Joaquim Venâncio, 2007. p. 177-224.

ORGANIZAÇÃO PAN-AMERICANA DA SAÚDE (Opas)/ORGANIZAÇÃO MUNDIAL DE SAÚDE (OMS). Atenção primária ambiental. Brasília, DF: Opas/OMS, 1999.

REIGOTA, Marcos. A educação ambiental frente ao esfacelamento da cidadania no governo Lula (2002-2006). In: RIBEIRO, Maria Auxiliadora; BERNARDES, Jefferson de Souza; LANG, Charles Elias. A produção na diversidade: compromissos éticos e políticos em psicologia. São Paulo: Casa do Psicólogo, 2007. p. 119-176. Disponível em: <www. rizoma3.ufsc.br/textos/173.pdf $>$. Acesso em: 25 jul. 2007.
SANTOS, Milton. Espaço e sociedade. Petrópolis: Vozes, 1979.

. Espaço e método. 4. ed. São Paulo: Nobel, 1997.

SANTOS, Alexandre Lima; RIGOTTO, Raquel Maria. Território e territorialização: incorporando as relações produção, trabalho, ambiente e saúde na atenção básica à saúde. Trabalho, Educação e Saúde, Rio de Janeiro, v. 8, n. 3, p. 387-406, nov. 2011.

SILVA, Natiane Carvalho. Paradigmas sanitários e problemas ambientais: os discursos dos agentes comunitários de saúde. Dissertação (Mestrado em Desenvolvimento Regional e Meio Ambiente) - Universidade Estadual de Santa Cruz, Ilhéus, 2008.

TAMBELLINI, Anamaria Testa; CÂMARA, Volney de Magalhães. A temática saúde e ambiente no processo de desenvolvimento do campo da saúde coletiva: aspectos históricos, conceituais e metodológicos. Ciência \& Saúde Coletiva, Rio de Janeiro, v. 3, n. 2, p. 47-59, 1998.

TRAPÉ, Carla Andrea; SOARES, Cássia Baldini. A prática educativa dos agentes comunitários de saúde à luz da categoria práxis. Revista Latino-Americana de Enfermagem, Ribeirão Preto v. 15, n. 1, 142-149, jan.-fev. 2007.

Recebido em 14/09/2011

Aprovado em 03/05/2012 